\title{
Structural dynamics and modeling of curcin protein: docking against pterin derivatives
}

\author{
Hemalatha Palanivel ${ }^{1} \cdot$ Murugesh Easwaran $^{2} \cdot{\text { Arun } \text { Meena }^{2} \cdot \text { Suryanarayanan Chandrasekaran }}^{3} \cdot$ M. Abdul Kader ${ }^{4}$. \\ Adhigan Murali ${ }^{4}$ (D)
}

(c) Springer Nature Switzerland AG 2019

\begin{abstract}
Jatropha species have been widely targeted for its use in oil and biodiesel production. The extraction of oil and biodiesel has been curbed due to the presence of curcin, a toxalbumin that can execute detailed toxic compounds. In silico approaches were undertaken to analyse the inhibition of curcin via pterin inhibitors, which show the structural similarities to ricin inhibitors. The identification of actual residues of predicted active sites, involved in binding with the ligands was accurately confirmed by molecular docking analysis. Among the eleven ligands screened in the present study, particularly, the folic acid showed the maximum docking score, which confirmed their hydrophobic site, hydrogen-bond donor and hydrogen-bond acceptor of folic acid, which could render the optimal biological function through inhibition of curcin. Graphic abstract
\end{abstract}

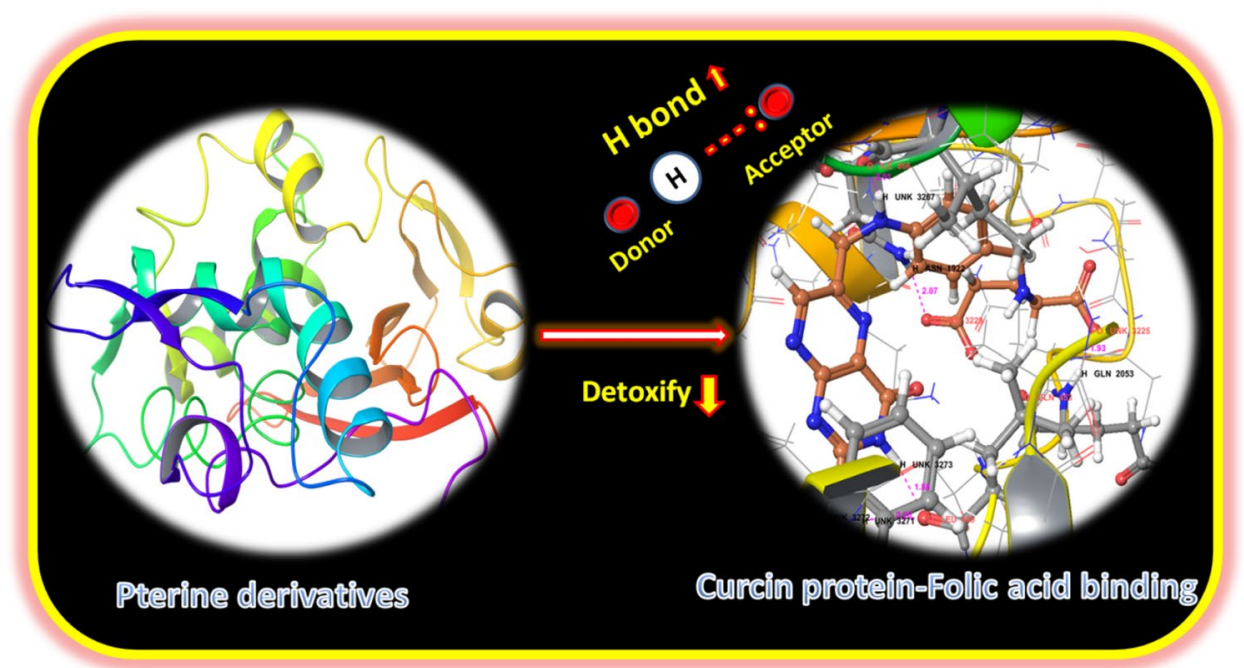

Keywords Curcin · Homology modeling $\cdot$ Molecular docking $\cdot$ Molecular dynamics $\cdot$ Detoxicity $\cdot$ Pterin

$\triangle$ Hemalatha Palanivel, latasenthil@gmail.com; Adhigan Murali, precymurali@gmail.com |'Department of Biotechnology, College of Biological and Chemical Engineering, Addis Ababa Science and Technology University, Post Box No 16417, Addis Ababa, Ethiopia. ${ }^{2}$ Department of Bioinformatics, Computational Biology Laboratory, Bharathiyar University, Coimbatore, Tamil Nadu 641046, India. ${ }^{3}$ Department of Chemistry, National Institute of Technology, Tiruchirappalli 620015 , India. ${ }^{4}$ School for Advanced Research in Polymers (SARP)-Advanced Research School for Technology and Product Simulation (ARSTPS), Central Institute of Plastics Engineering and Technology (CIPET), Ministry of Chemicals and Fertilizers, Govt. of India, Chennai 600032, India.

SN Applied Sciences (2019) 1:812 | https://doi.org/10.1007/s42452-019-0752-5

Received: 22 April 2019 / Accepted: 10 June 2019 / Published online: 1 July 2019 


\section{Introduction}

Jatropha species have been associated with the spurge family belonging to family of Euphorbiacea and is native to tropical conditions of North America and Mexico, Asian countries, South America and Africa. [1, 2]. Jatropha species targeted particularly for their efficient biodiesel and oil production. As the profitability of seeds from Jatropha curcas has been attributed to 40 per cent of biodiesel production, rural areas of Thailand, southern parts of India and Malaysia [3, 4]. Jatropha curcas $(J C)$ was traditionally used in medical field particularly in veterinary purposes [5]. Some of the compounds such as curcin and curcacycline $A$, have better antitumor activities in $J C$ plant and their substances like phorbol esters, which are highly poisonous to animal and human [6].

Although, the biodiesel and oil production from Jatropha curcas has apparently evidenced gainful, the seed protein curcin and seed phorbol have been recognized as highly toxic. The toxicity portrayed by curcin, toxalbumin, is detected to inactivate ribosomes, thus inactivating the protein synthesis in eukaryotes $[7,8]$. Although, this protein is supposed to be intricated in plant defence system, such as anti-fungal, anti-bacterial, anti-tumour and anthelminthic properties in practice and theory, the toxicity of this protein has rendered in children with overdoses and hepatoxicity $[9,10]$. The curcin, which is a storage protein; therefore, the seed cake of jatropha can also serve to be nutritionally supplement, if the toxins are removed and it has potential inhibitory effect upon protein synthesis in reticulocyte lysate [11]. Moreover, curcin was found that there is no toxicity in HeLa cells and normal cells and curcin have better antitumor activity related to the $\mathrm{N}$-glycosidase activity [12]. The ribosome inactivating proteins (RIPs) are defence proteins at higher plant species, which are unswervingly targeted toward herbivores. Curcin is similar to ricin and arbin proteins of Ricinus communis and Abrusprecatorius, which inactivating protein synthesis [13]. Ribosome-inactivating proteins (RIPs) from plants are mephitic and many protein syntheses by catalytically destruct ribosomes with rRNA $\mathrm{N}$-glycosidase activity, when entering a eukaryotic cell. The protein can enzymatically hew the specific glycosidic bond of an adenine residue, thus deterring protein synthesis by prying the binding of the 285 rRNA to the elongation factors [14]. There are two types of RIPs, Type I RIPs are single-polypeptide proteins with molecular mass of about 23-32 kD, although type II RIPs have molecular mass of $60 \mathrm{kD}$ and entails of 2 chains together with a disulphide bond. Remarkably, curcin which fits to RIP I have more toxicity and they were modeled by composites approach of 3D structure predictions [15].

\section{SN Applied Sciences}

As per our acquaintance, there is no information on ligand designed for hampering curcin toxicity till date. In silico structural and dynamic study showed that the curcin protein binds to adenine of $r-R N A$, since RNA based inhibitors and their analogues can also be promising curcin inhibitors. As a binding mode of ricin inhibitors to the adenine pocket of r-RNA is almost similar to curcin [16]. Hence, we have selected pterin derivatives as ligands [17] for our investigation for inhibition of curcin through in silico approaches (see Fig. 1).

\section{Materials and methods}

\subsection{Protein structural modeling}

The structural information of protein is essential to annotate its biological function. The amino acid sequence of curcin was retrieved from NCBI Genbank [18] (Accession no. ABZ04128.1) sequence of length 309 residues. Multiple template proteins for curcin protein sequence were selected using BLASTp tool [19]. The crystal structure information for the template proteins were obtained from Protein Data Bank [20]. To obtain most similar protein sequence, multiple sequence alignment was carried out using Genious Pro (http://www.geneious.com/). Based on this alignment a 3-dimensional homologue (Fig. 2) was modelled using Prime module of Schrodinger suite and using the same also performed loop refinement, sidechain prediction and energy minimisation of the modeled protein [21]. The modeled and pre-refined structure of curcin protein was validated by analysing Ramachandran plot obtained using PROCHECK server [22].

\subsection{Active site prediction of modeled protein}

As the actual binding sites of modeled protein were unknown, the most probable active sites of protein were identified using Sitemap module of Schrödinger suite. This module determines most likely binding site of protein with ligands. The sites are calculated based on grid calculation and mapped as per their characteristics features like hydrophobic, hydrophilic, hydrogen-bond donor, hydrogen-bond acceptor, surface map and metal binding sites [23, 24]. Hence, the ligands having complementary features were likely to bind to the predicted binding sites.

\subsection{Molecular docking study and analysis}

The selected ligands were docked with modeled curcin protein by using Glide module of Schrodinger suite. The stereoisomer, tautomer, ionisation states of the ligands were generated by Epik module made available by ligand 
<smiles>Nc1nc(=O)c2nc(C(=O)O)cnc2[nH]1</smiles>

1. Pterin-6-carboxylic acid<smiles>Nc1nc(=O)c2nc(CC(O)C(O)CO)cnc2[nH]1</smiles>

2. Neopterin<smiles>Nc1nc(=O)c2nc(CNc3ccc(C(=O)O)cc3)cnc2[nH]1</smiles>

3. Pteroic acid<smiles>NC(=O)c1cnc2[nH]c(N)nc(=O)c2n1</smiles>

4. Folic acid<smiles>NCNC(=O)c1cnc2[nH]c(N)nc(=O)c2n1</smiles>

7. 7-hydrazide pterin<smiles>Nc1nc(=O)c2nc(C(=O)NCc3ccco3)cnc2[nH]1</smiles>

8. $N$-(furanylmethyl)-7-carbamoyl pterin<smiles>CNC(=O)c1cnc2[nH]c(N)nc(=O)c2n1</smiles>

6. $N$-methyl-7-carbamoyl pterin<smiles>CCC(=O)c1cnc2[nH]c(N)nc(=O)c2n1</smiles>

9. 7-propionyl pterin<smiles>Nc1nc(=O)c2nc(C(=O)NCc3ccc(F)cc3)cnc2[nH]1</smiles>

10. $N$-(4-fluorobenzyl)-7-carbamoyl pterin<smiles>Nc1nc(=O)c2nc(C(=O)NCCNc3ccccc3)cnc2[nH]1</smiles>

11. $N$-(2-(phenylamino)ethyl-7-carbamoyl pterin

Fig. 1 Chemical structure of selected pterine derivatives

preparation tool of Schrodinger suite. The metallic ions and residue protonation states were allotted using Epik model. Succeeding the structural enhancements, all the target structures were energy-minimized using the OPLS2001 force field [25]. The modeled curcin protein preparation was performed by using protein preparation Wizard of Schrodinger suite, wherein the protein structure was refined by adding hydrogen, assigning bond-order, deleting hetero atoms and energy optimization. An extra precision, flexible ligand docking was performed for receptor by generating a grid of dimension 27,27 and $27 \AA$ ( $x, y$ and $z$ ) centred at all residues of the receptor.

\subsection{Molecular dynamics simulation study}

The root mean squared deviation (RMSD) analysis of total trajectory was done to observe the extent of fluctuation of the complex from its mean state. The obtained ligand pose having highest binding affinity with the protein (i.e.) Protein-Floic acid complex, a molecular dynamics simulation 


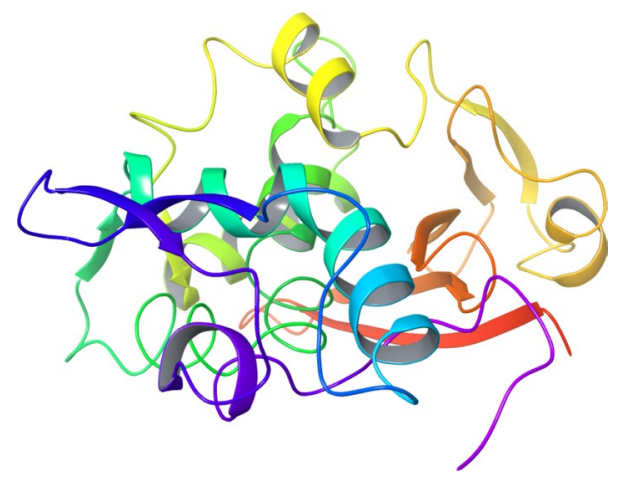

Fig. 2 Modeled and energy minimised 3-dimensional structure of curcin protein

was performed using Macro model of Schrodinger suite (Schrodinger LLC,NY, 2013). An equilibrium run for 100 ps was performed followed by production run of $1 \mathrm{~ns}$. Each sample was minimised before writing to trajectory after 10 ps intervals.

\section{Results and discussion}

\subsection{Homology modelling and its validation}

The unique phase of RIP research had already evoked and the investigation to advance in diverse directions. Among them, the investigation on new plant proteins with the competency to obstruct the protein synthesis by using the same mechanism as ricin has been attempt through this study. Shrubs known for their pernicious or poisonous nature were also studied, crotin and curcin were sequestered from Croton tiglium and Jatropha curcas respectively in 1976 [26]. Many of these RIPs are competent to deadenylate not only rRNA but also divergent polynucleotide substrates such as DNA, poly(A) and several types of RNA, with $m R N A$, tRNA, bacterial rRNA and viral RNA [27]. RIPs are classified as three types according to the number of subunits and the organization of the precursor sequences. RIPs are two-domain proteins, with the active site located in the cleft between the $\mathrm{N}$ - and $\mathrm{C}$-terminal domains. Explicating facts of the association between molecular structure and actual biological terminal point is crucial for efficacious, deliberate drug discovery. Molecular docking is an extensively endorsed tool for lead identification.

No significant similarity was observed in any of the PDB templates in N-Terminal sequence encouraged us to undertake the study. Numerous homology modelling software's were employed to model protein and the analogy of the outcome pointed out that the model achieved by SWISSMODEL is more agreeable than those generated by the other programs [28]. This method would give

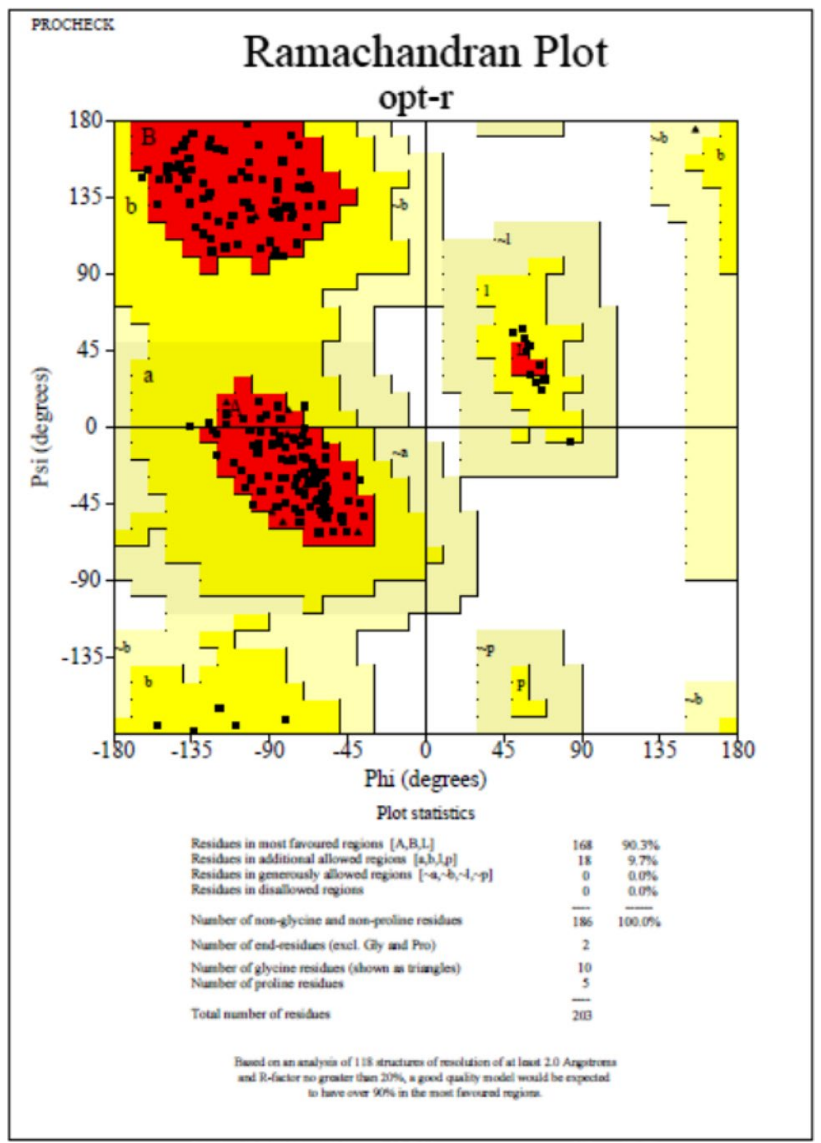

Fig. 3 Ramachandran plot of curcin protein

pragmatic results based on the hypothesis that the tertiary structures of two proteins will be analogous if their sequences have been intersected [29].

Homology modelling was customarily a technical mode of when a well-defined liaison among the target protein and at least one recognised structure is acquired. Homology modelling is routinely used in many applications such as virtual screening or rationalising the effect of sequence variation [30]. This line of work will be quite results cantered on the conjecture that the tertiary structures of two proteins will be similar if their sequences are associated. The homologue model of curcin protein was modeled and was validated and authenticated through Ramachandran plot (Fig. 3). Among 203 of total residues, 168 residues were found in highly favourable region which makes around $90.3 \%$ of total residues. The main 3D model of curcin resulted from the structural modelling was illustrated in Fig. 2.

The backbone ratification of the established model has been corroborated by using Ramachandran plot picked up through PROCHECK. The distribution of phi and psi angles for the amino acid residues was denoted by Ramachandran plot. The built model was proven to be highly 
plausible; hence no residue $(0 \%)$ has been found the distance in the disallowed region of Ramachandran Plot. The evaluation and assessment of 3D model of curcin with the unveiled a well-matched glide score. Similar results were accomplished with molecular modelling programs in Trypanosoma brucei [31]. The projected model that evidenced and well endorsed in terms of geometry and energy contours recommended that the model is legitimate and feasible for further molecular docking studies [32, 33].

\subsection{Molecular dynamic study}

Probing the stability of protein-ligand complex and its performance to be contingent on the dynamic state that the vital to ascertain the drug likeness of a compound. Molecular dynamic is a consistent computational method to fathom any system in real time. Molecular dynamics (MD) analysis are regularly performed in chemical research to constrain cooperation with qualitative and quantitative networks between sub microscopic dynamics and perceived biochemical behaviour. The predicted model was used for molecular dynamic studies. The model was primarily honed by amending the missing side chains, earmarking the bond orders and supplementing polar hydrogen atoms to the receptors [34]. The hydrogen bond has been complemented, matching to the physiological PH state in order to emulate the protein structure. Moreover, to subside the close contact conformation, the supplementary hydrogen atom was energy curtailed. The potential energy was calculated by OPLS_2005 force field. The charges and long range ordered interactions and calculations were performed using force field parameters. For the structural refinement process, the prime module of Schrodinger package was used in this study [35]. Total trajectories for 100 samples were generated and no bonds and angles were set constrained. The simulation was performed in water system in water solvent, at physiological $\mathrm{pH}$ at $300 \mathrm{~K}$ temperature using PRCG minimisation method for 1000 interactions, 1.5 fs time steps and 0.05 convergence threshold. The output of an MD is period resolved sequence of atomic positions built on the mobilities and interactions, which are physically allied beside with complete information of energy linked quantities like kinetic energy, potential energy temperature and pressure, the contemporary finding supporting this for each point in time [36].

The protein-ligand binding should persist intact in order to implement mandatory function in the dynamic environment for given physiological condition $[37,38]$. Molecular dynamics study provided clear view of the behaviour of curcin protein-folic acid complex with respect to time. A $1 \mathrm{~ns}$ molecular dynamic simulation run suffices to obtain the protein-ligand complex stability information. The root mean squared analysis showed that the complex is stable with deviation of $2.5 \AA$ on an average after 380 ps (see Fig. 4). The same was supported in prediction of molecular interaction of platelet glycoprotein [39]. This implies that the complex formed with the protein by compound folic acid does not destabilise or denature the protein. Hence compounds or analogues of folic acid possessing required binding sites feature can be designed and investigated to detoxicate of curcin.

\subsection{Active site prediction and molecular docking}

Computational techniques to recognize and depict the functional sites on proteins have progressively turn into significant area of research [40]. The unsurpassed active site was ideal on the site score and hydrophobic or hydrophilic areas, which embraces restored binding activity [41]. As no co-crystal structure was existing for curcin protein, the active site was predicted. Two active sites have been identified (Fig. $5 \mathrm{a}$ and $\mathrm{b}$ ). The binding site (a) represented moderate hydrophobic, hydrogen-bond acceptor and hydrogen-bond donor region although the binding site (b) denoted only hydrogen-bond acceptor and hydrogenbond donor region. The active site information provided most probable binding site of ligand. Receptor-ligand study delivers better understanding about the binding mode of a drug with the receptor. Various conformation and orientation of a ligand with respect to protein can influence the binding ability of ligand. Molecular docking [42] was performed, in order to gain detailed information regarding curcin protein and ligand binding affinity and to predict among the selected ligands, which ligand conformation binds well to the protein.

Analysis of various energy factors contributing to the total energy required for protein-ligand interaction of prime importance to estimate the binding energy. The kind of protein residue participating in the protein ligand

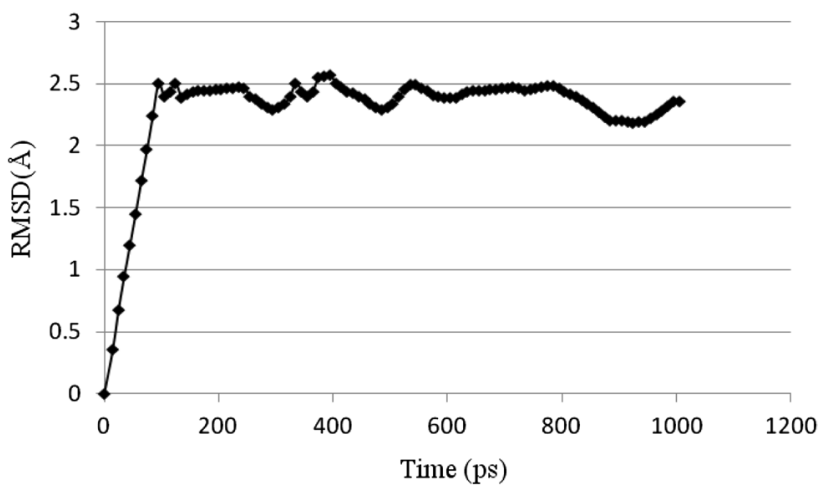

Fig. 4 The RMSD plot for protein-Folic acid complex for 1 ns MD simulation run 
Fig. 5 Predicted active sites of modeled curcin protein shown in mesh contour map representation; yellow mesh represents hydrophobic map, red mesh represents hydrogenbond acceptor map and blue mesh represents hydrogenbond donor map. The brown and green threads are $\beta$ and a sheets and loop regions in the predicted active site of the modeled curcin
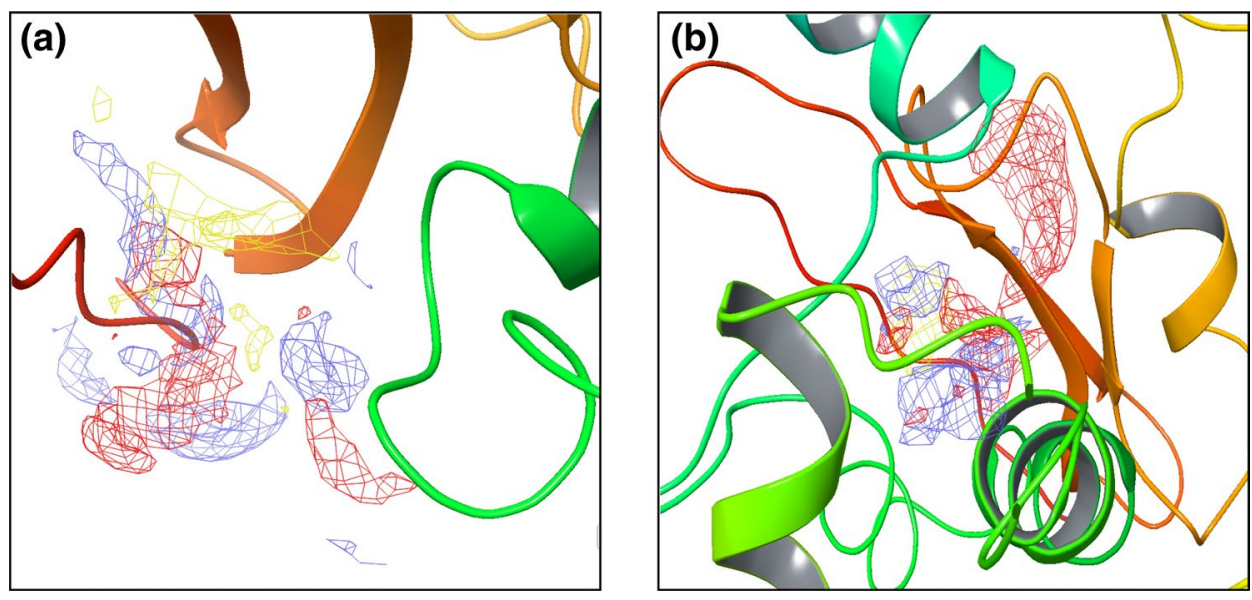

Table 1 Pose viewer analysis of protein-ligand complex

\begin{tabular}{ll}
\hline Pterin derivatives & GlideScore (Kcal/mol) \\
\hline Folic acid & -9.980503 \\
N-(2-(phenylamino)ethyl-7-carbomyl_pterin & -7.601365 \\
Pteroic acid & -7.453686 \\
Neopterin & -7.411637 \\
N-(furanylmethyl)-7-carbomyl_pterin & -6.626247 \\
N-(4-fluorobenzyl)-7-carbomyl_pterin & -6.362965 \\
7-hyrazide_pterin & -6.080808 \\
N-methyl-7-carbomyl_pterin & -6.046335 \\
7-carbomyl_pterin & -5.89647 \\
7-propionyl_pterin & -5.781886 \\
Pterin-6-carboxylic acid & -5.22884
\end{tabular}

interaction adds the respective energy term of the total binding score and provides the best interacting ligand pose. The XP GlideScore, multi ligand scoring function along with a composite Emodel gives the best ligand pose ranking by combining Glide score, non-bonded interaction energy, excess internal energy in case of flexible ligand docking; the excess internal energy and hydrogen bond energy. This concurred with the aforementioned studies, which directed that the effect of atomic charges of the ligand may influence the electrostatic and polar in binding free energy of the structure [43]. Observing protein-ligand interaction at atmospheric scale provided further information of the binding site residue of the modeled protein and ligand residue. The Glide score details and the site-site interaction of protein-ligand complex are presented in Tables 1 and 2 respectively. The identification of actual residues of predicted active site, involved in binding with the ligand of accurate conformation has been answered by molecular docking task. The available conformers of selected ligands obtained after ligand preparation were docked with the modeled protein [44, 45]. From the post dock analysis, it was observed that as compared to all
Table 2 Site-site interaction details of protein binding site residue and ligand

\begin{tabular}{lll}
\hline Protein residue & Ligand (folic acid) atom & $\begin{array}{l}\text { H bond } \\
\text { distance } \\
(\AA)\end{array}$ \\
\hline ASN (H) & O & 2.07 \\
GLN (H) & O & 1.93 \\
ILE (O) & $H$ & 2.01 \\
LEU (O) & $H$ & 1.88 \\
& $H$ & 2.26 \\
PHE (O) & H & 1.97 \\
\hline
\end{tabular}

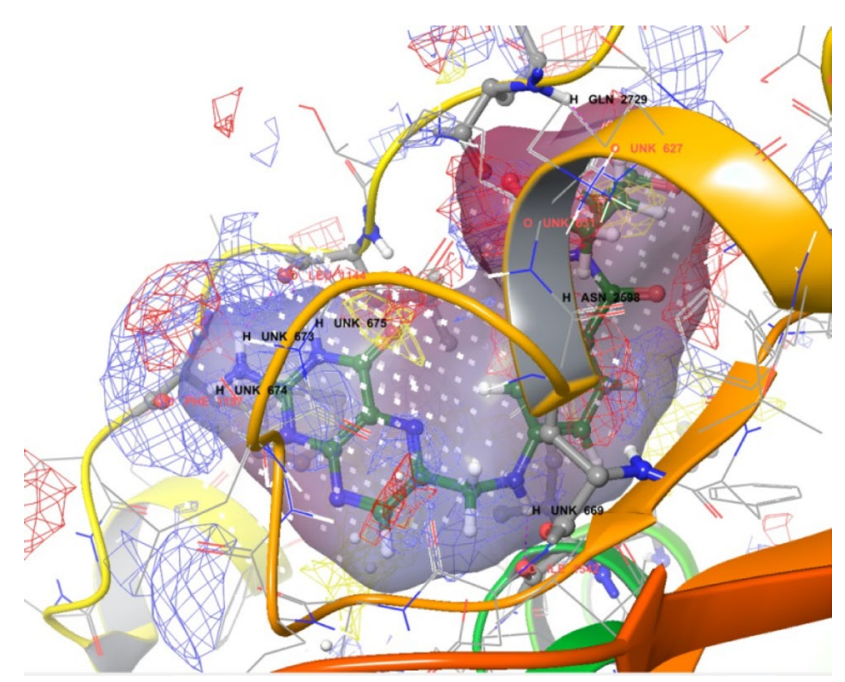

Fig. 6 Binding of compound, folic acid at predicted active site

eleven ligands, the compound folic acid showed highest interaction with the protein (Glide Score: $-9.980503 \mathrm{kcal} /$ mol) (Table 1). Folic acid possess six hydrogen bond donors, five hydrogen bond acceptors and two hydrophobic site, which was found to bind at the predicted binding pocket (a) as expected (Fig. 6). Folic acid showed 
Fig. 7 3-D representation of interaction profile of modeledcurcin protein- folic acid complex binding site; hydrogen bond is shown by pink dotted line

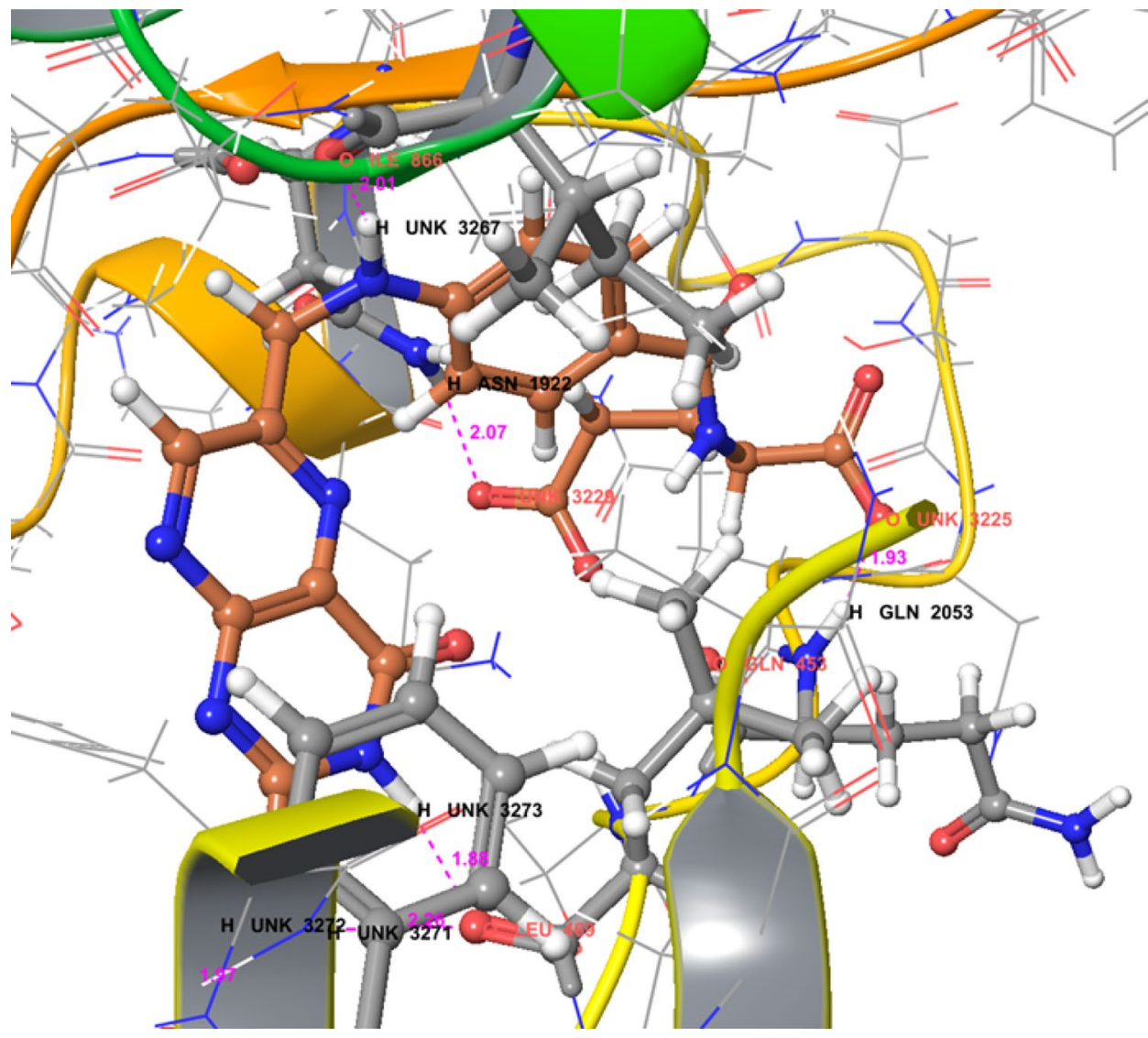

three strong hydrogen bond interactions with GLY, LEU and $\mathrm{PHE}$ residue of protein, whereas weak hydrogen bond interaction with ASN and ILE residues (Fig. 7). Moreover compound N-(2-(phenylamino)ethyl-7-carbomyl_pterin resembling folic acid also showed well interaction with protein possessing binding score of $-7.601365 \mathrm{kcal} / \mathrm{mol}$ although less than folic acid (Table 1). The compound, $\mathrm{N}$-(2-(phenylamino) ethyl-7-carbomyl_pterin possess four hydrogen-bond donor, five hydrogen-bond acceptor and one hydrophobic site. This implies that the hydrophobic site, hydrogen-bond donor and hydrogen-bond acceptor are the key features for a compound in order to bind efficiently to the curcin protein and exhibit respective optimal biological function.

\section{Conclusion}

For the first time, a structural and dynamic study of curcin protein has been reported to understand the binding sites and binding factors, which are involved in the curcin protein and identify compound to detoxify the protein. The active site prediction of modeled curcin protein displayed the utmost credible active binding pocket accountable for ligand binding. The molecular docking of designated pterin derivatives rendered folic acid as best interacting compound for which hydrophobic, hydrogen-bond donor, hydrogen-bond acceptor features were attributed as key for binding with the protein which was comparatively similar to $\mathrm{N}$-(2-(phenylamino) ethyl-7-carbomyl_pterin compound. The molecular dynamics simulation study for 1 ns further strengthened the view that the protein remains stable after binding with folic acid. From this study it can be inferred that folic acid can be a compound to reduce detoxicity of curcin, moreover analogues possessing above mentioned key features can be designed and synthesized to acquire improvised detoxicity behaviour.

Acknowledgements The author (A. Murali) grateful to the Department of Science and Technology (DST), Govt. of India, Grant No: DST/ INSPIRE/04/2018/001762 for DST Inspire Faculty.

\section{Compliance with ethical standards}

Conflict of interest The authors declare that they have no conflict of interest. 


\section{References}

1. Barceloux DG (2008) Barbados nut (Jatropha curcas L.) Medical toxicology of natural substances: foods, fungi, medicinal herbs, plants, and venomous animals. Wiley, Hoboken, pp 829-831

2. Chomchai $C$, Kriengsunthornkij W, Sirisamut T et al (2011) Toxicity from ingestion of Jatropha curcas ('Saboodum') seeds in Thai children. Southeast Asian J Trop Med Pub Health 42:946-951

3. Kulkarni ML, Sreekar H, Keshavamurthy KS, Shenoy N (2005) Jatropha curcas-poisoning. Ind J Pediatr 72(1):75-76. https:// doi.org/10.1007/BF02760586

4. Patil PD, Deng S (2009) Optimization of biodiesel production from edible and non-edible vegetable oils. Fuel 88:1302-1306. https://doi.org/10.1016/j.fuel.2009.01.016

5. Abdel Gadir WS, Onsa TO, Ali WEM, El Badwi SMA, Adam SEI (2003) Comparative toxicity of Croton macrostachys, Jatropha curcas and Piper abyssinica seeds in Nubian goats. Small Rumin Res 48(1):61-67. https://doi.org/10.1016/S0921 -4488(02)00181-5

6. Evans FJ, Taylor SE (1983) Pro-inflammatory, tumour-promoting and anti-tumour diterpenes of the plant families euphorbiaceae and thymelaeaceae. Progress in the chemistry of organic natural products, vol 44. Springer, Vienna

7. Barbieri L, Battelli MG, Stirpe F (1993) Ribosome-inactivating proteins from plants. Biochem Biophys Acta 1154(3-4):237282. https://doi.org/10.1016/0304-4157(93)90002-6

8. Barbieri L, Valbonesi P, Bonora E, Gorini P, Bolognesi A, Stirpe F (1997) Polynucleotide:adenosine glycosidase activity of ribosome-inactivating proteins: effect on DNA, RNA and poly (A). Nucleic Acids Res 25:518-522. https://doi.org/10.1093/ nar/25.3.518

9. Jummai AT, Okoli BJ (2014) Curcin from Jatropha curcas seed as a potential anthelmintic. Adv Med Plant Res 2:47-49

10. Krawetz JE, Boston RS (2000) Substrate specificity of a maize ribosome-inactivating protein differs across diverse taxa. Eur J Biochem 267:1966-1974. https://doi.org/10.104 6/j.1432-1327.2000.01200.x

11. Lin J, Li YX, Zhou XW, Tang KX, Chen F (2003) Cloning and characterization of a curcin gene encoding a ribosome inactivating protein from Jatropha curcas. DNA Seq 14(1):311-317. https://doi.org/10.1080/1042517031000119348

12. Manosroi J, Boonpisuttinant K, Manosroi W, Manosroi A (2012) Anti-proliferative activities on HeLa cancer cell line of Thai medicinal plant recipes selected from MANOSROI II database. J Ethnopharmacol 142(2):422-431. https://doi.org/10.1016/j. jep.2012.05.012

13. Zhang Y, Li C et al (2017) Curcin C, a novel type I ribosomeinactivating protein from the post-germinating cotyledons of Jatropha curcas. Amino Acids 49(9):1619-1631. https://doi. org/10.1007/s00726-017-2456-8

14. Willy JP et al (2001) Ribosome-inactivating proteins from plants: more than RNA N-glycosidases. FASEB J 15(9):14931506. https://doi.org/10.1096/fj.00-0751 rev

15. Srivastava M, Gupta SK, Abhilash PC, Singh N (2012) Structure prediction and binding sites analysis of curcin Jatropha curcas using computational approaches. J Mol Model 18(7):29712979. https://doi.org/10.1007/s00894-011-1320-0

16. Yan $X$ et al (1997) Structure-based identification of a ricin inhibitor. J Mol Biol 266:1043-1049. https://doi.org/10.1006/ jmbi.1996.0865

17. Jasheway K, Pruet J, Anslyn EV, Robertus JD (2011) Structurebased design of ricin inhibitors. Toxins 3:1233-1248. https:// doi.org/10.3390/toxins3101233
18. Benson DA, Karsch-Mizrachi I, Lipman DJ et al (2000) GenBank. Nucleic Acids Res 28(1):15-18. https://doi.org/10.1093/ nar/28.1.15

19. Altschul SF, Madden TL, Schaffer AA, Zhang J, Zhang Z, Miller W, Lipman DJ (1997) Gapped BLAST and PSIBLAST: a new generation of protein database search programs. Nucleic Acids Res 25:3389-3402. https://doi.org/10.1093/nar/25.17.3389

20. Sussman JL, Lin D, Jiang J, Manning NO, Prilusky J, Ritter O, Abola EE (1998) Protein Data Bank (PDB): database of threedimensional structural information of biological macromolecules. Acta Crystallogr D 54:1078-1084. https://doi. org/10.1107/S0907444998009378

21. Suite Schrodinger (2009) The induced fit docking protocol. Schrodinger, LLC, New York

22. Laskowski RA, MacArthur MW, Moss DS, Thornton JM (1993) PROCHECK: a program to check the stereochemistry of protein structure. J Appl Crystallogr 26:283-291. https://doi. org/10.1107/S0021889892009944

23. Ananthakrishnan SJ, Sambath Kumar B et al (2013) Supramolecular assembly in side-chain conjugated thiophene copolymers. RSC Adv 3:8331-8340. https://doi.org/10.1039/C3RA0 0029J

24. Ananthakrishnan SJ, Elumalai V et al (2014) Offsetting the problem of charge trapping in white polymer light-emitting diodes using a fluorenone-based luminogen. J Mater Chem C. 2:90359044. https://doi.org/10.1039/C4TC01722F

25. Kaminski GA, Friesner RA, Tirado-Rives J, Jorgensen WL (2001) Evaluation and reparametrization of the OPLS-AA force field for proteins via comparison with accurate quantum chemical calculations on peptides. J Phys Chem B 105(28):6474-6487. https ://doi.org/10.1021/jp003919d

26. Stripe F, Pession-brizzi A, Lorenzoni E, Stroccji L, Montanaro L, Sperti $S$ (1976) Studies of the proteins from the seeds of Croton tiglium and of Jatropha curcas. Biochem J 156:1-6. https://doi. org/10.1042/bj1560001

27. Barbieri L, Battelli MG, Stirpe F (1993) Ribosome-inactivating proteins from plants. Biochem Biophys Acta 1154(3-4):237-282. https://doi.org/10.1016/0304-4157(93)90002-6

28. Konstantin A, Lorenza B, Jürgen K, Torsten S (2006) The SWISSMODEL workspace: a web-based environment for protein structure homology modelling. Bioinformatics 22(2):195-201. https ://doi.org/10.1093/bioinformatics/bti770

29. Sun M, Li Z, Zhang Y, Zheng Q, Sun C-C (2005) Homology modeling and docking study of cyclin-dependent kinase (CDK). Bioorg Med Chem Lett 15(11):2851-2856. https://doi. org/10.1016/j.bmcl.2005.03.088

30. Hillisch A, Pineda LF, Hilgenfeld R (2004) Utility of homology models in the drug discovery process. Drug Discov Today 9:659666. https://doi.org/10.1016/S1359-6446(04)03196-4

31. Amaro RE, Swift RV, McCammon JA (2007) Functional and structural insights revealed by molecular dynamics simulations of an essential RNA editing ligase in Trypanosoma brucei. PLoS Negl Trop Dis 1(2):e68. https://doi.org/10.1371/journal.pntd.0000068

32. Wu B, Zhang Y, Kong J, Zhang X, Cheng S (2009) In silico predication of nuclear hormone receptors for organic pollutants by homology modeling and molecular docking. Toxicol Lett 191(1):69-73. https://doi.org/10.1016/j.toxlet.2009.08.005

33. Srinivasan P, Sudha A, Umamaheswaria N et al (2012) Modeling of quorum sensing regulatory protein, LuxR from Vibrio harveyi and in silico prediction of active drugs. Int J Curr Sci 2:1-8

34. Kalyanamoorthy SA, Chen YPP (2013) Quantum polarized ligand docking investigation to understand the significance of protonation states in histone deacetylase inhibitors. J Mol Gr Model 44(1):44-53. https://doi.org/10.1016/j.jmgm.2013.05.002

35. Jacobson MP, Pincus DL, Rapp CS, Day TJ, Honig B, Shaw DE, Friesner RA (2004) A hierarchical approach to all-atom protein 
loop prediction. Proteins 55:351-367. https://doi.org/10.1002/ prot.10613

36. Zwier MC (2018) Bridging the microscopic and macroscopic in thermodynamics with molecular dynamics simulations: lab exercises for undergraduate physical chemistry. In ACS Symposium Series, vol 1279, pp 33-48. https://doi.org/10.1021/ bk-2018-1279.ch003

37. Lauro FV, Francisco DC, Marcela RN et al (2019) Preparation of a steroid-oxazole-1,2'-[1,3] oxazete] derivative: biological and theoretical evaluation of its interaction with a kinase protein $\left(\mathrm{CK}_{2}\right)$. SN Appl Sci 1:361. https://doi.org/10.1007/s42452-019-0378-7

38. Vakili-Nezhaad GR, Al-Wadhahi M, Gujarathi AM et al (2019) Molecular dynamics simulation of water-graphene nanofluid. SN Appl Sci 1:214. https://doi.org/10.1007/s42452-019-0224-y

39. Shiozaki S, Takagi S, Goto S (2016) Prediction of molecular interaction between platelet glycoprotein Iba and Von Willebrand Factor using molecular dynamics simulations. J Atheroscler Thromb 23(4):455-464. https://doi.org/10.5551/jat.32458

40. Campbell et al (2003) Ligand binding, functional site location similarity and docking. Curr Opin Struct Biol 13:389-395. https ://doi.org/10.1016/S0959-440X(03)00075-7
41. Almagro JC, Beavers MP, Hernandez-Guzman F, Maier J, Shaulsky $J$ et al (2011) Antibody modeling assessment. Proteins 79:30503066. https://doi.org/10.1002/prot.23130

42. Rahul C, Lalit S, Sanket B, Abhay C (2015) Protein modeling and docking of curcurin against neuraminidase, hemagglutinin proteins of pandemic influenza H1N1/2009. J Pharm Sci Res 7:70-75

43. Aaron W, Kambiz K, PärSöderhjelm IN, Ulf R (2006) Ligand affinities predicted with the $\mathrm{MM} / \mathrm{pbsa}$ method: dependence on the simulation method and the force field. J Med Chem 49(22):6596-6606. https://doi.org/10.1021/jm0608210

44. Ghalib RM, Mehdi SH, Hasan T et al (2019) 2,2'-(2-Oxopropane1,3-diyl)bis-(2-hydroxy-1H-indene-1,3(2H)-dione): synthesis, crystal, electronic and molecular docking studies. SN Appl Sci 1:351. https://doi.org/10.1007/s42452-019-0366-y

45. Waseem M, Suhaib M, Sherwani AF (2019) Modelling and analysis of gradient effect on the dynamic performance of threewheeled vehicle system using Simscape. SN Appl Sci 1:225. https://doi.org/10.1007/s42452-019-0235-8

Publisher's Note Springer Nature remains neutral with regard to jurisdictional claims in published maps and institutional affiliations. 